\title{
Armored brain
}

\section{Cérebro blindado}

Farrukh S. Chaudhry', José Biller', Christopher M. Loftus², John A. Braca III²

A 47-year-old man with a history of macrocephaly was diagnosed with spontaneous non-traumatic bilateral calcified subdural hematomas (SDHs) (Figures 1-2). He had chronic, daily, bilateral, dull headaches for many years. His head circumference was $62 \mathrm{~cm}$, but his neurological examination was unremarkable. Calcified chronic SDHs are an unusual entity and a rare complication of chronic shunting for hydrocephalus ${ }^{1}$. Although not previously diagnosed, we suspect he may have suffered from arrested hydrocephalus. Due to his increased head circumference, stretching of bridging subdural veins may have developed, slowly enlarging the bilateral SDHs, which later became calcified. The encased appearance of the brain with bilateral and extensive chronic calcified SDHs is described as the "armored brain," also known as "matryoshka head" after the famous Russian nesting dolls ${ }^{2-3}$. Our observation is unique because our patient never underwent a shunting procedure.

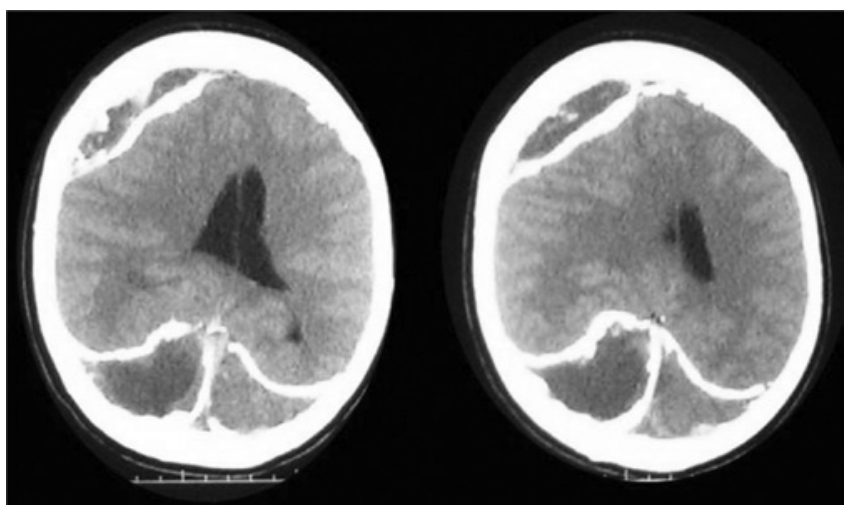

CT: computed tomography, SDH: subdural hematoma.

Figure 1. Axial head CT without contrast showing bilateral SDHs with calcification giving an appearance of an armored brain (double skull).

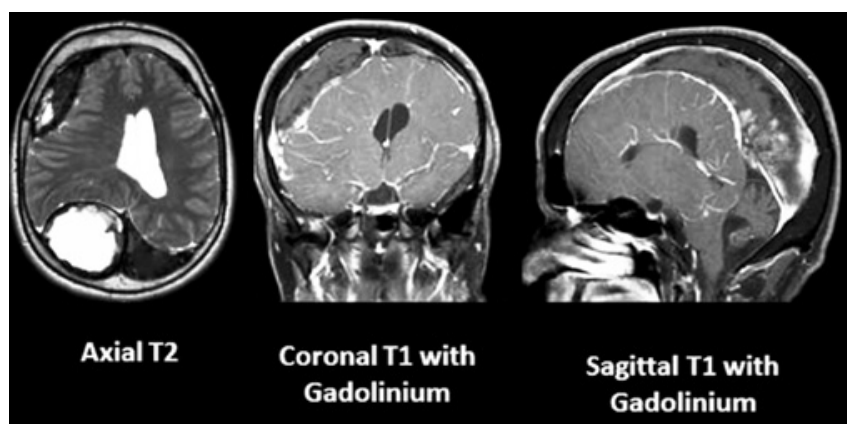

MRI: magnetic resonance imaging, SDH: subdural hematoma.

Figure 2. Brain MRI demonstrating the extent of bilateral calcified SDHs encasing the brain giving appearance of an armored brain.

\section{References}

1. Petraglia AL, Moravan MJ, Jahromi BS. Armored brain: a case report and review of the literature. Surg Neurol Int 2011;2:120.

2. Sgaramella E, Sotgiu S, Miragliotta G, Fotios Kalfas Crotti FM.
"Matrioska head". Case report of calcified chronic subdural hematoma. J Neurosurg Sci 2002;46:28-31.

3. Kaplan M, Akgün B, Seçer HI. Ossified chronic subdural hematoma with armored brain. Turkish Neurosurg 2008;18:420-424.

\footnotetext{
1Department of Neurology, Loyola University Chicago, Stritch School of Medicine, Maywood IL, U.S.A.;

${ }^{2}$ Department of Neurological Surgery, Loyola University Chicago, Stritch School of Medicine, Maywood IL, U.S.A.

Correspondence: Farrukh Chaudhry; Loyola University Medical Center, 2160 South First Avenue / Maguire Building / Suite 2700; 60181 Maywood IL - U.S.A.; E-mail: farrukhc@gmail.com

Conflict of interest: There is no conflict of interest to declare.

Received 29 January 2013; Received in final form 13 May 2013; Accepted 20 May 2013.
} 